\title{
On Two-Dimensional Supramolecular Polymers Embodying Large Unilamellar Vesicles in Water
}

\author{
Shigui Chen, Shane M. Polen, Lu Wang, Makoto Yamasaki, Christopher M. Hadad and Jovica D. Badjić* \\ badjic@chemistry.ohio-state.edu \\ Department of Chemistry and Biochemistry, The Ohio State University, 100 West 18th Avenue, Columbus, \\ $\mathrm{OH} 43210$
}




\section{Content}

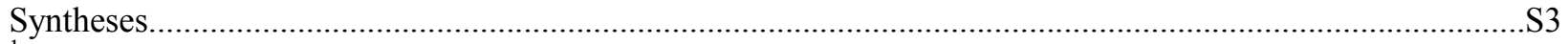

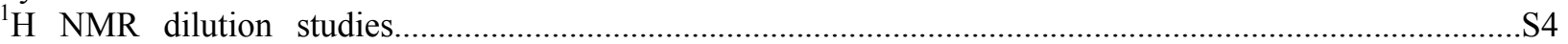

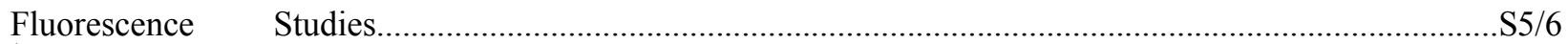

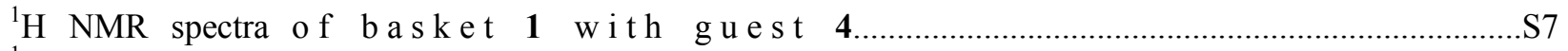

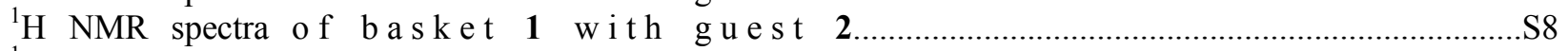

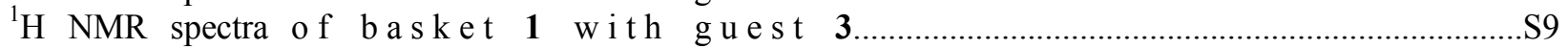

Molecular Mechanics (Monte-Carlo Conformational Search)....................................... 11

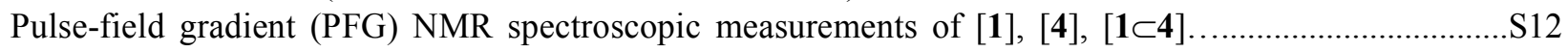

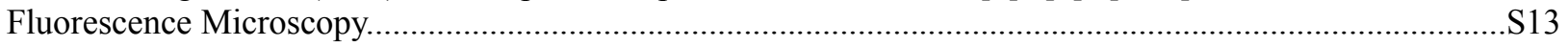

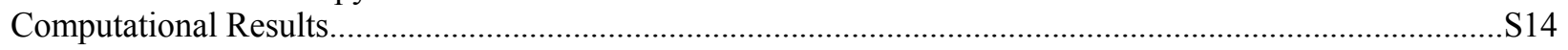


Syntheses: Basket $\mathbf{1}$ and monovalent guests $\mathbf{2}$ and $\mathbf{3}$ were obtained using an already reported protocol (see Chen, S. ; Yamasaki, M.; Polen, S.; Gallucci, J.; Hadad, C. M.; Badjic, J. D. J. Am. Chem. Soc. 2015, 137, 12276). Compound 4 (see Scheme 1 below): Benzidine $(50 \mathrm{mg}, 0.27 \mathrm{mmol})$ was dissolved in EtOH $(4 \mathrm{~mL})$, followed by the addition of 1-(2,4-dinitrophenyl)-4-pyridinium chloride (168 $\mathrm{mg}, 0.60 \mathrm{mmol})$. Then the mixture was refluxed for $24 \mathrm{~h}$. After refluxing, the solvents were dried under reduced pressure and purified by $\mathrm{Al}_{2} \mathrm{O}_{3}$ (dichloromethane/methanol $\left.=20: 1\right)$ to yield $62 \mathrm{mg}(60 \%)$ of compound 4 as a light yellow solid. ${ }^{1} \mathrm{H}$ NMR $\left(600 \mathrm{MHz}, \mathrm{CD}_{3} \mathrm{OD}\right): \delta(\mathrm{ppm})=9.35(\mathrm{~d}, J=6.2 \mathrm{~Hz}, 4 \mathrm{H}), 8.87-8.84(\mathrm{~m}, 2 \mathrm{H}), 8.37-8.34(\mathrm{~m}, 4 \mathrm{H}), 8.17(\mathrm{~d}$, $J=8.5 \mathrm{~Hz}, 4 \mathrm{H}), 8.03(\mathrm{~d}, J=8.5,4 \mathrm{H}) .{ }^{13} \mathrm{C} \mathrm{NMR}\left(150 \mathrm{MHz}, \mathrm{CD}_{3} \mathrm{OD}\right): \delta(\mathrm{ppm})=146.75,144.69,143.03,142.08$, $129.13,128.25,125.02$. HR-MS (ESI): calculated $(\mathrm{M}-2 \mathrm{Cl})^{2+}=155.0730$, found 155.0761.

Scheme S1 Synthesis of bivalent guest 4

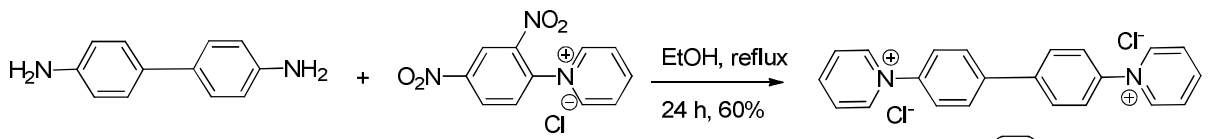



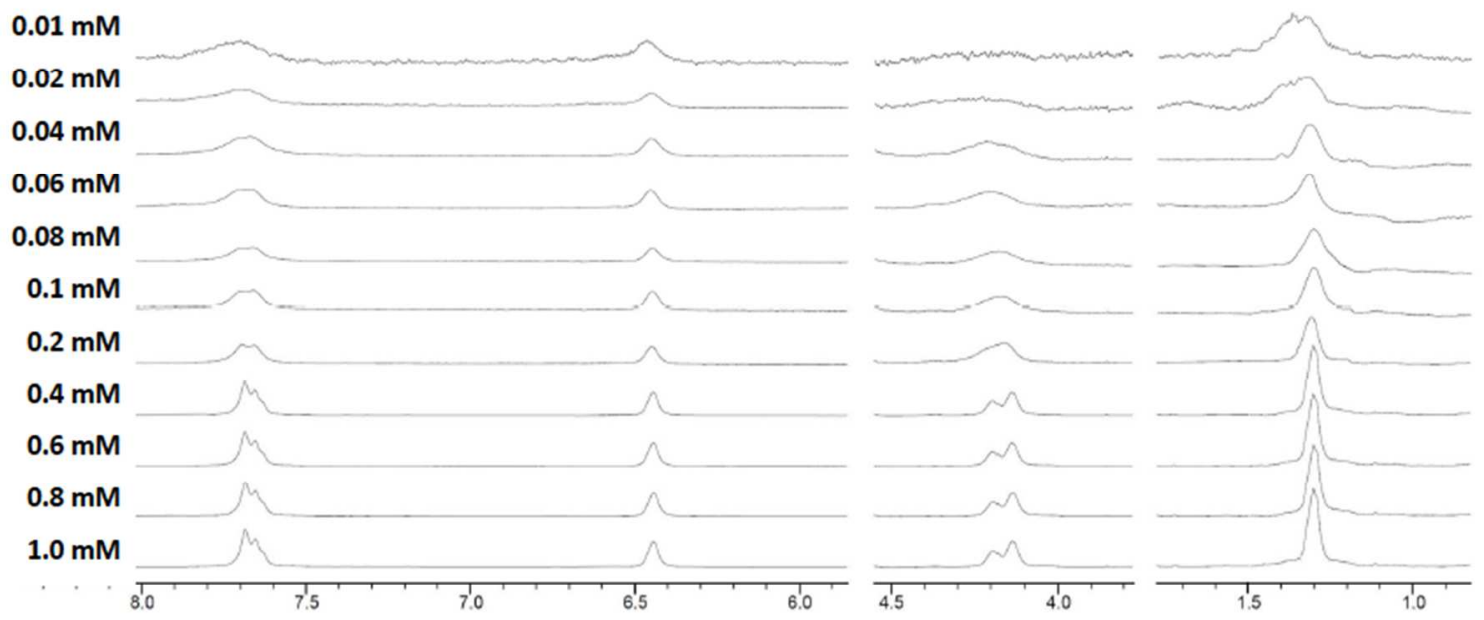

Figure S1. Sections of ${ }^{1} \mathrm{H}$ NMR spectra $(600 \mathrm{MHz}, 298.0 \mathrm{~K} ; 5 \mathrm{~mm}$ triple-resonance inverse (TXI) cryoprobe with Z-Gradients) of $\mathrm{D}_{2} \mathrm{O}$ solutions of basket 1 at different concentrations. Note the apparent and increased (to a various degree) broadening (but not sharpening) of the signals with the dilution. The broadening could have resulted from relatively low concentrations of the basket with a greater $\mathrm{S} / \mathrm{N}$ ratio also contributing to a poor resolution of the signal splitting; the number of scans: $0.01-0.02 \mathrm{mM}(512) ; 0.04-0.1 \mathrm{mM}$ (400); $0.2-1.0 \mathrm{mM}$ (100). In addition, a change in the solvation of the electrical double layer at the vesicular interface and dynamics of baskets could also have an effect on the appearance of the spectra. 


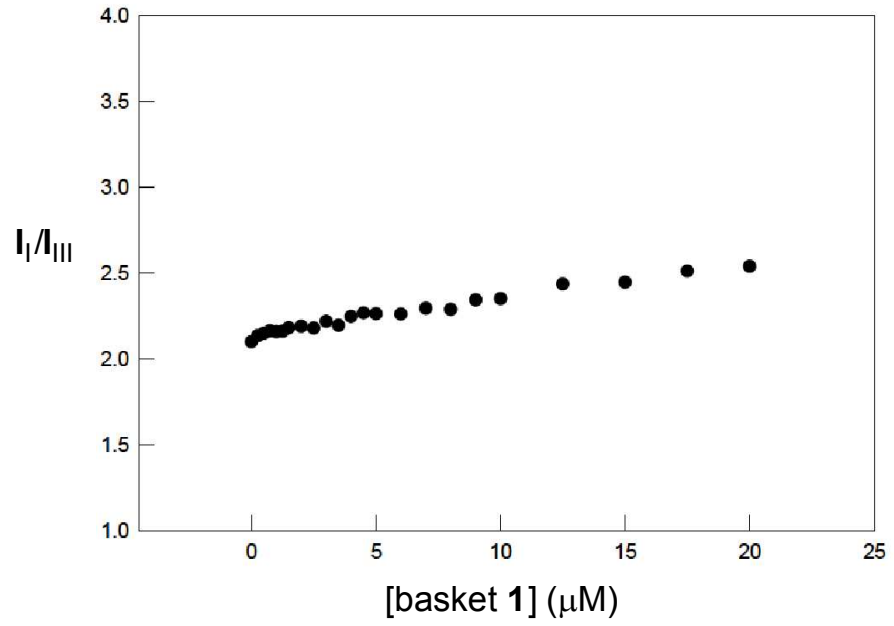




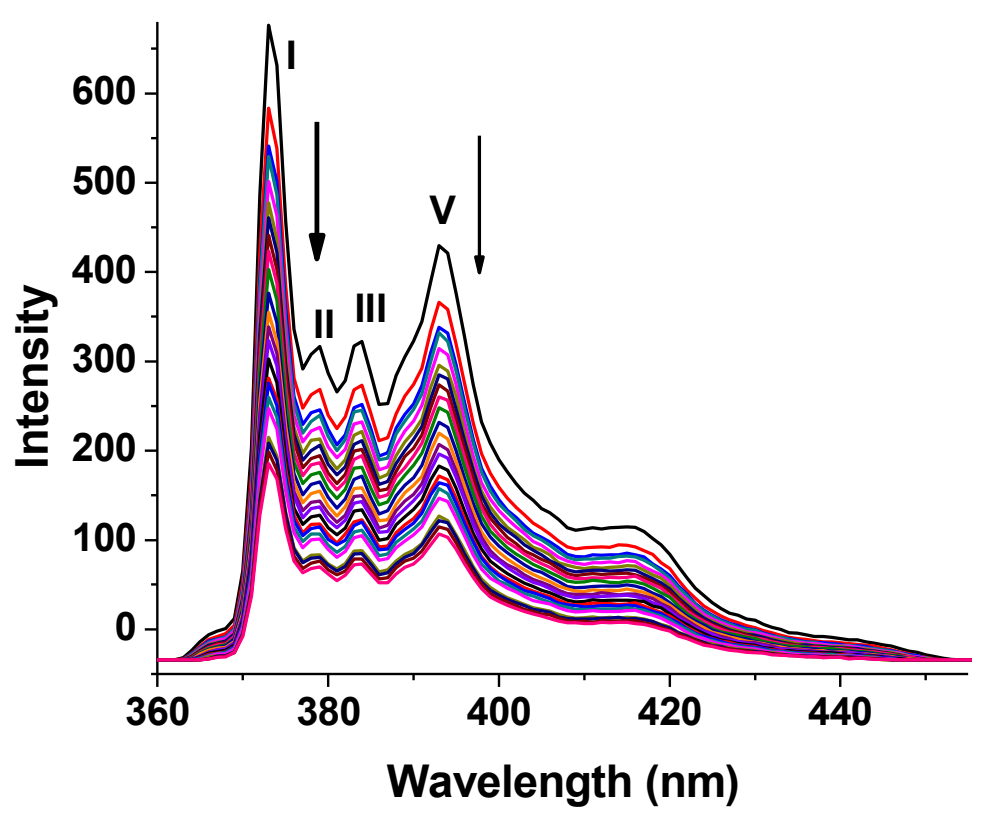

Figure S2. (Top) Fluorescence spectra $\left(\lambda_{\text {ex }}=334 \mathrm{~nm}\right)$ of pyrene $\left(2.0 \times 10^{-6} \mathrm{M}\right)$ in the presence of dual-cavity 1 $\left(0 \mu \mathrm{M}\right.$ (top spectrum; $0.25-20 \times 10^{-6} \mathrm{M}$, from top to bottom) in $\mathrm{H}_{2} \mathrm{O}$ at $298 \mathrm{~K}$. The spectroscopic measurements were completed with the excitation at $334 \mathrm{~nm}$ and the use of excitation and emission slits of 10 and $1.5 \mathrm{~nm}$, respectively. (Bottom) The ratio of the intensity of $\mathrm{I}_{\mathrm{I}}(373 \mathrm{~nm})$ and $\mathrm{I}_{\mathrm{III}}(384 \mathrm{~nm})$ is only increasing slightly (c.a. 0.4) without any abrupt transitions; note that the incorporation of pyrene from water into the hydrophobic vesicular layer is expected to lower the $\mathrm{I}_{\mathrm{I}} / \mathrm{I}_{\mathrm{III}}$ ratio (see $J$. Chem. $E d .1997,74,1227$ ). 


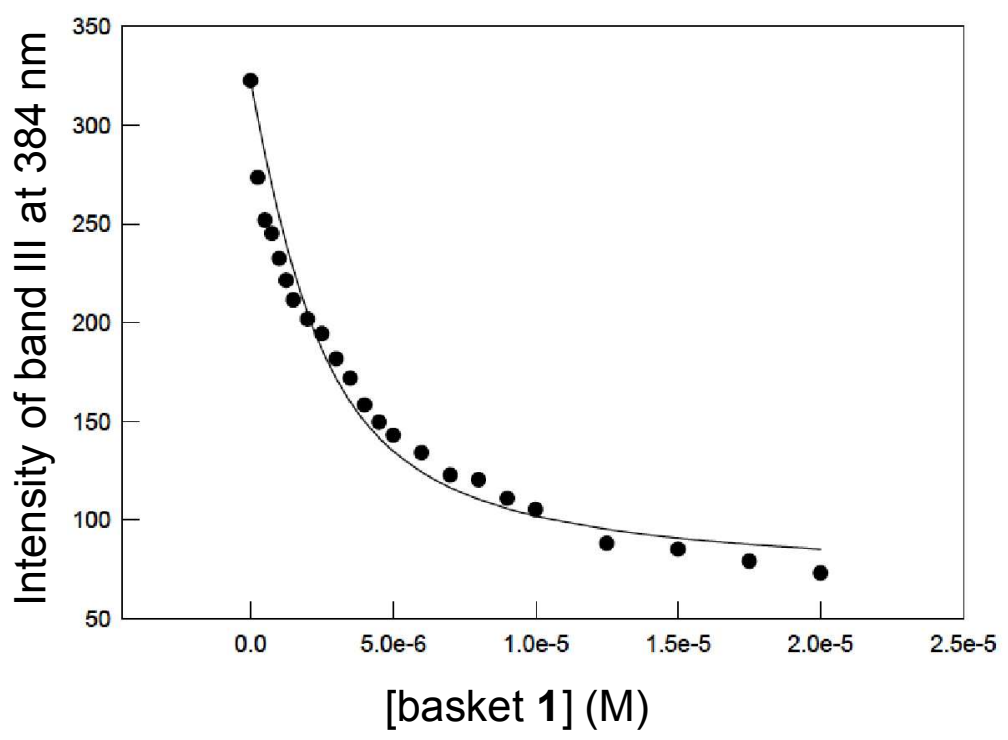

Figure S3. The binding isotherm was obtained from the fluorescence spectroscopic data (Figure S5) whereby the addition of a standard solution of basket $1\left(1 \mathrm{mM}\right.$ in $\left.\mathrm{H}_{2} \mathrm{O}\right)$ to pyrene $(2.0 \mu \mathrm{M})$ was monitored at $\lambda_{\text {em }}=384$ $\mathrm{nm}$ (band III) as a function of the concentration of basket 1 . The nonlinear least-square analysis of the binding data fits reasonably well $\left(R^{2}=0.95\right)$ to $1: 1$ stoichiometric model $\left(K_{\text {app }}=8.1 \cdot 10^{5} \mathrm{M}^{-1}\right)$ to suggest the predominant formation of equimolar $[\mathbf{1} \subset$ pyrene] complex; note that additional binding events, corresponding to the formation of higher order complexes, could also be contributing to the complexation. 


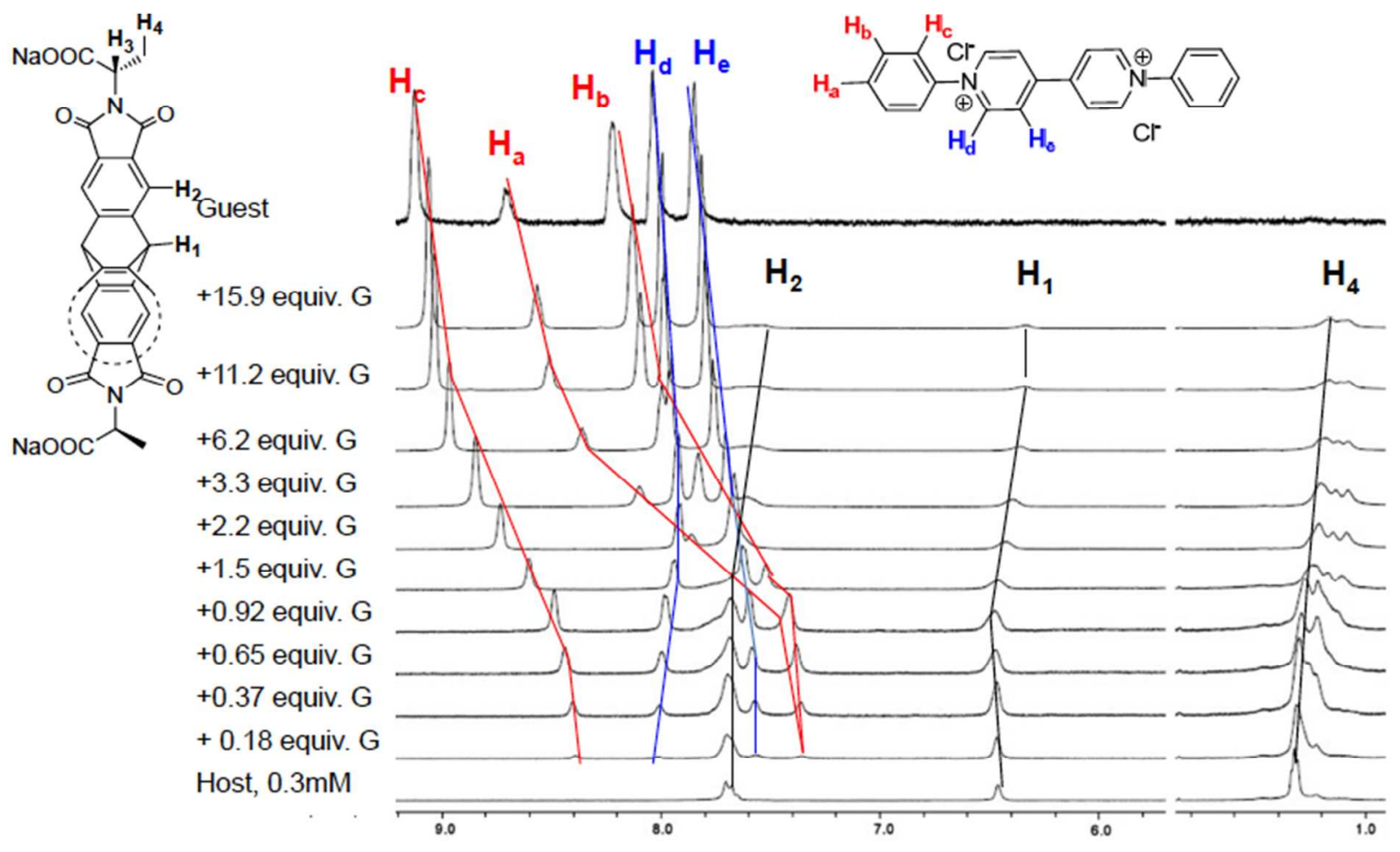

Figure S4. ${ }^{1} \mathrm{H}$ NMR spectra $(600 \mathrm{MHz}, 298.0 \mathrm{~K})$ of a solution of basket $\mathbf{1}\left(0.3 \mathrm{mM}\right.$ in $\left.\mathrm{D}_{2} \mathrm{O}\right)$ obtained upon an incremental addition of $12.0 \mathrm{mM}$ compound 4 (0.18-15.9 molar equivalents) in $\mathrm{D}_{2} \mathrm{O}$. 

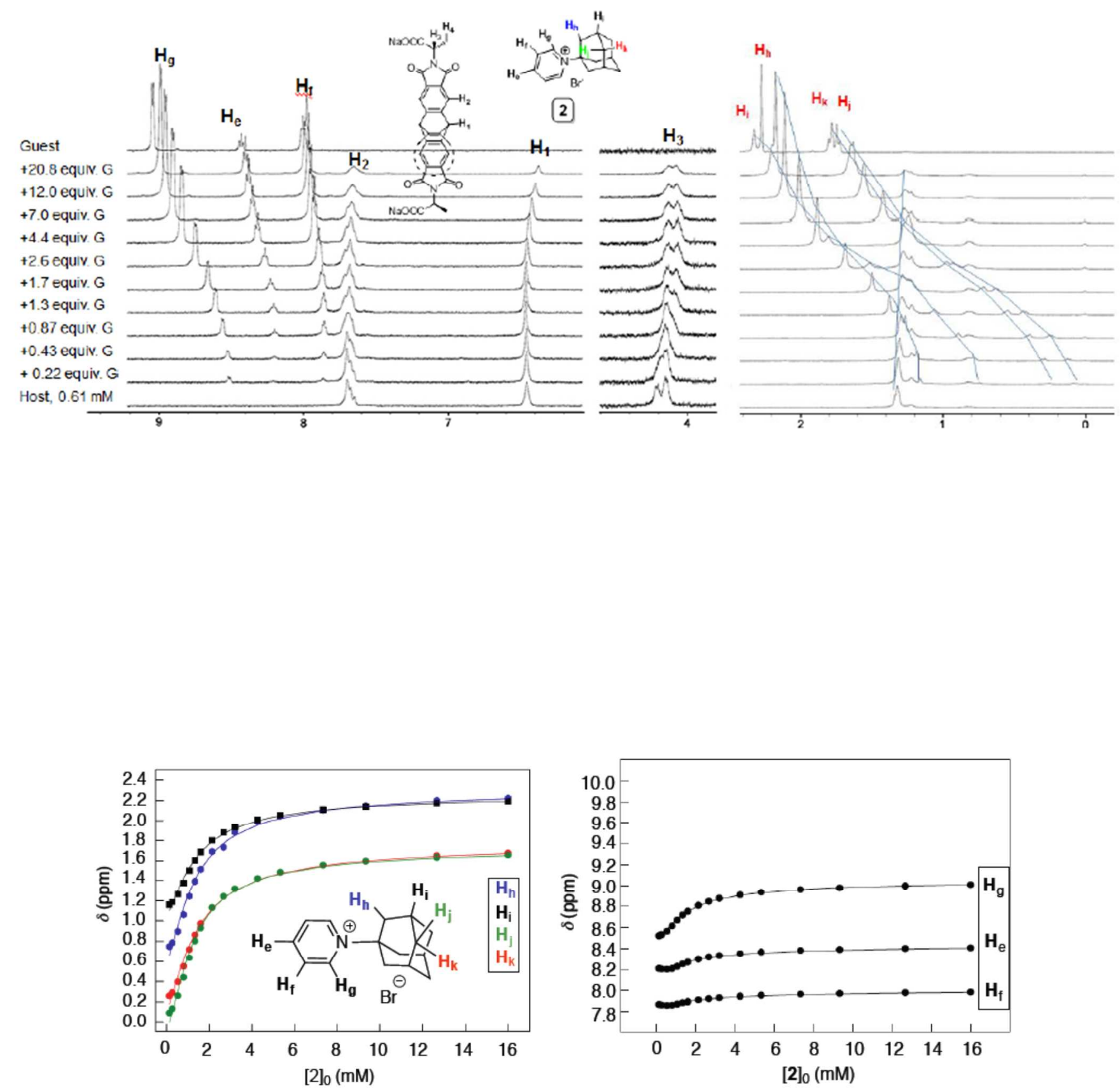

Figure S5. Top: Sections of ${ }^{1} \mathrm{H}$ NMR spectra $(600 \mathrm{MHz}, 298.0 \mathrm{~K})$ of a solution of basket $\mathbf{1}\left(0.61 \mathrm{mM}\right.$ in $\left.\mathrm{D}_{2} \mathrm{O}\right)$ obtained upon an incremental addition of compound $2\left(0.22-20.8\right.$ mol equivalents) in $\mathrm{D}_{2} \mathrm{O}$. Bottom: ${ }^{1} \mathrm{H}$ NMR Chemical shifts $(600 \mathrm{MHz})$ of resonances corresponding to protons of guest 2 as its solution $(60.0 \mathrm{mM})$ was incrementally added to basket $1(0.61 \mathrm{mM})$ in $\mathrm{D}_{2} \mathrm{O}$ at $298.0 \mathrm{~K}$ (see Badjic et al. J. Am. Chem. Soc. 2015, 137, 12276; the proton labeling of guest $\mathbf{2}$ is taken from the published study). 

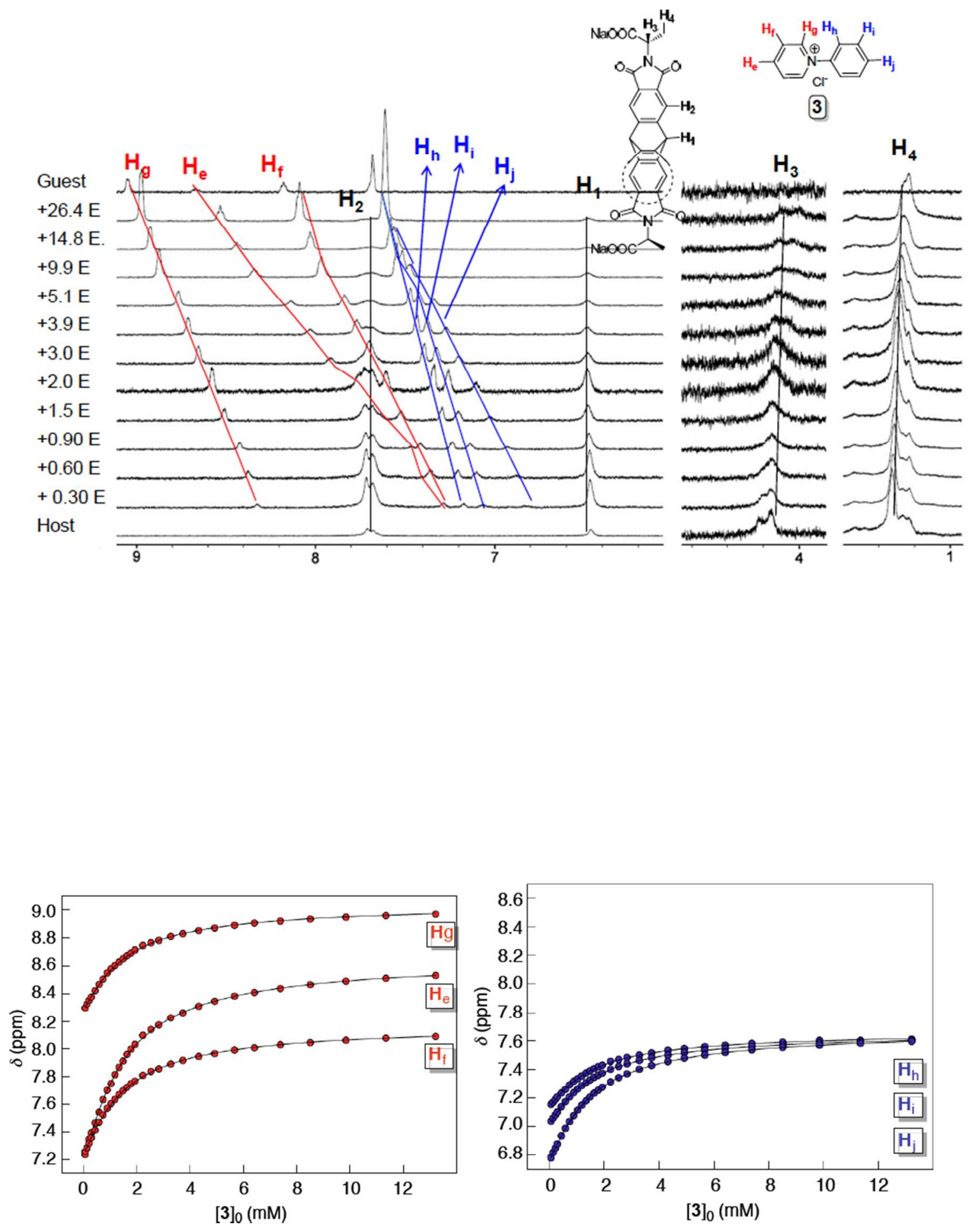

Figure S6. Top: Sections of ${ }^{1} \mathrm{H}$ NMR spectra $(600 \mathrm{MHz}, 298.0 \mathrm{~K})$ of a solution of basket $1\left(0.5 \mathrm{mM}\right.$ in $\left.\mathrm{D}_{2} \mathrm{O}\right)$ obtained upon an incremental addition of compound 3 (0.3-26.4 mol equivalents) in $\mathrm{D}_{2} \mathrm{O}$. Bottom: ${ }^{1} \mathrm{H}$ NMR Chemical shifts $(600 \mathrm{MHz}, 298.0 \mathrm{~K})$ of resonances corresponding to protons of guest $\mathbf{3}$ as its solution (31.3 
$\mathrm{mM}$ ) was incrementally added to basket $\mathbf{1}(0.5 \mathrm{mM})$ in $\mathrm{D}_{2} \mathrm{O}$ (see Badjic et al. J. Am. Chem. Soc. 2015, 137, 12276; the proton labeling of guest $\mathbf{3}$ is taken from the published study).

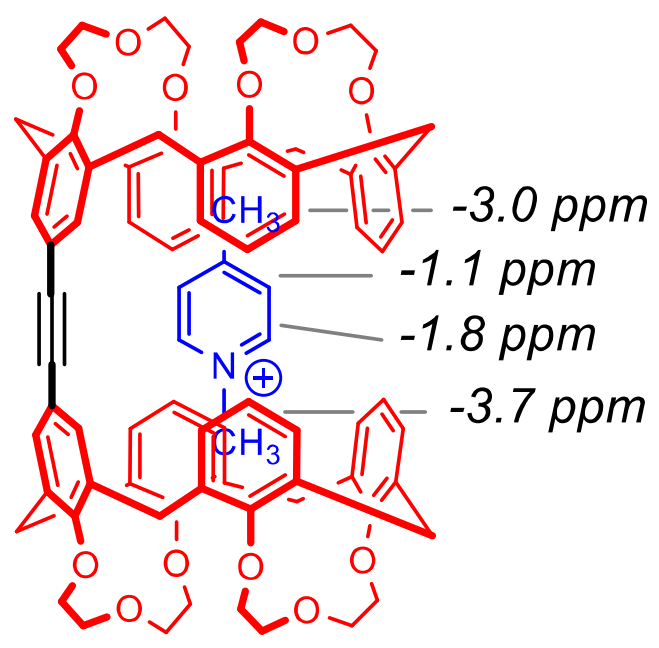

Figure S7. ${ }^{1} \mathrm{H}$ NMR chemical shifts of cationic guests (blue) spanning two cavities of the host (red) from Arduini, A.; Pochini, A.; Secchi, A. Eur. J. Org. Chem. 2000, 2325. Note a gradual change in the magnetic perturbation of the guest's resonances, akin to our observation in Figure 3A. 

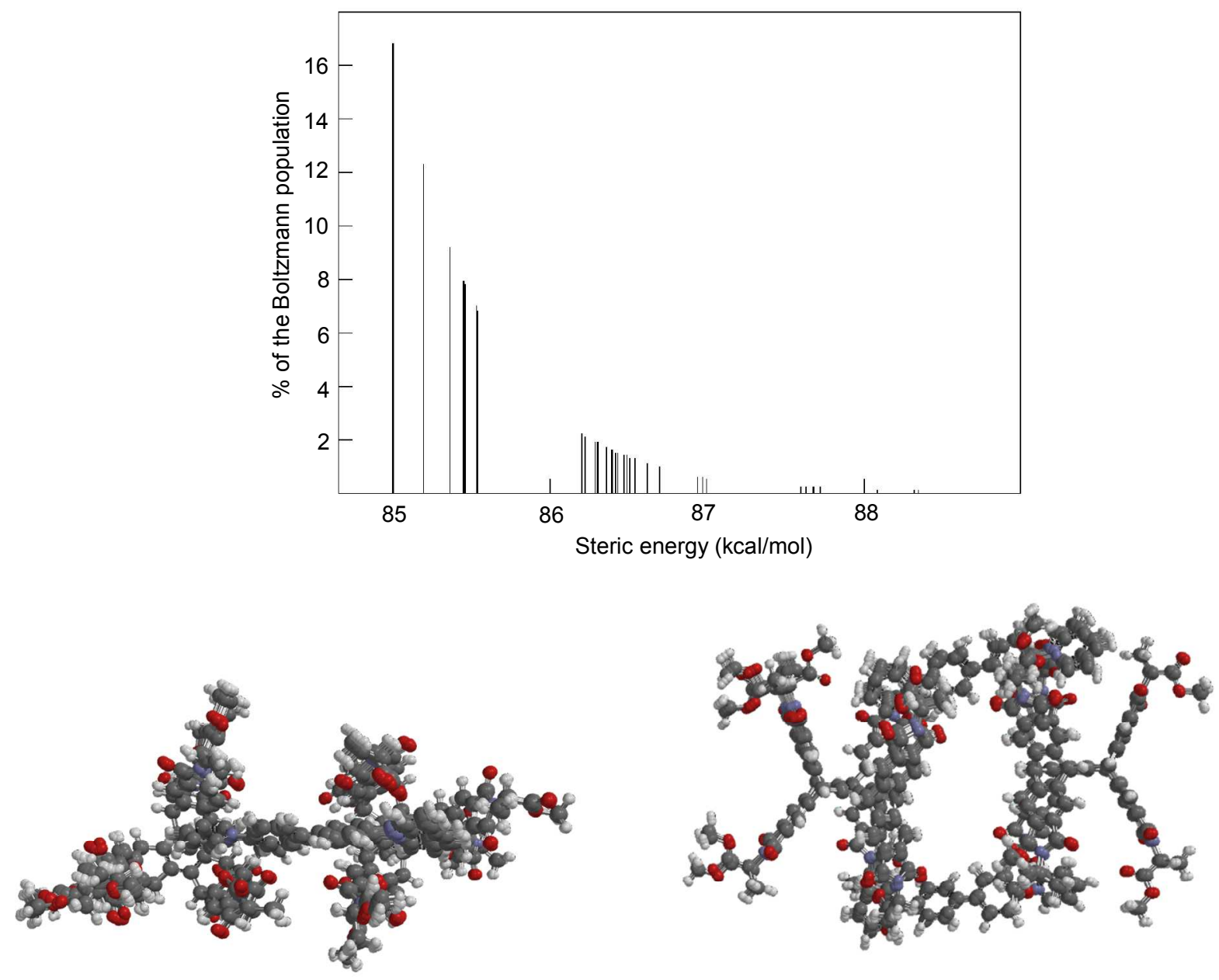

Figure S8. (Top) A vertical bar chart plot showing the Boltzmann distribution (given in percentage) of computed 91 conformers of $[\mathbf{1} \subset \mathbf{4}]_{2}$ complex as a function of the corresponding steric energies $(\mathrm{kcal} / \mathrm{mol})$. The Monte Carlo conformational search was completed with Spartan and MMFFaq force field (500 steps) in an implicit water solvent to take into an account the solvation. (Bottom) A top and side view of all conformers contributing to $97 \%$ of the Boltzmann population with computed steric energies of $85-87 \mathrm{kcal} / \mathrm{mol}$. 

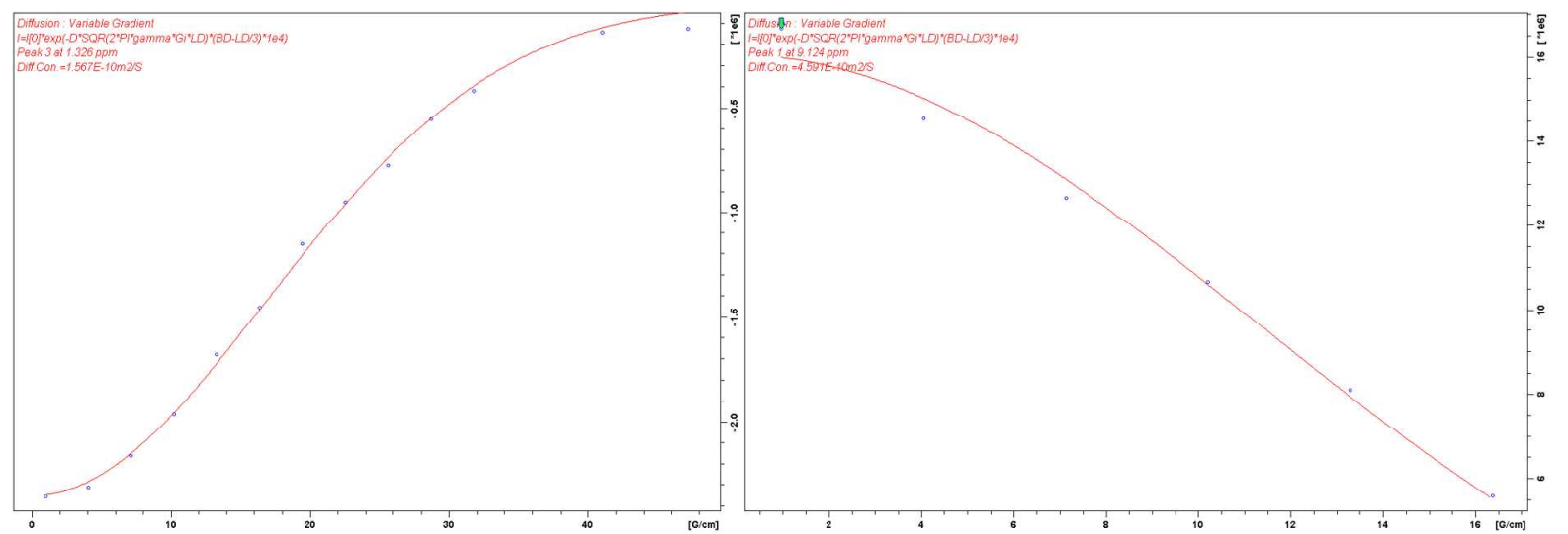

Figure S9. Nonlinear least-square analysis of the pulse-field gradient (PFG) NMR spectroscopic measurements for: (left) basket $1\left(0.3 \mathrm{mM}\right.$ in $\mathrm{D}_{2} \mathrm{O}$ at $298.0 \mathrm{~K} ; \mathrm{CH}_{3}$ group) gave the apparent diffusion coefficient $D^{(\mathbf{1})}=1.58 \pm 0.02 \times 10^{-10} \mathrm{~m}^{2} / \mathrm{s}$ while (right) guest $4\left(0.3 \mathrm{mM}\right.$ in $\mathrm{D}_{2} \mathrm{O}$ at $298.0 \mathrm{~K} ; \mathrm{H}_{\mathrm{c}}$ proton $)$ gave the apparent diffusion coefficient $D^{(4)}=4.59 \pm 0.01 \times 10^{-10} \mathrm{~m}^{2} / \mathrm{s}$.

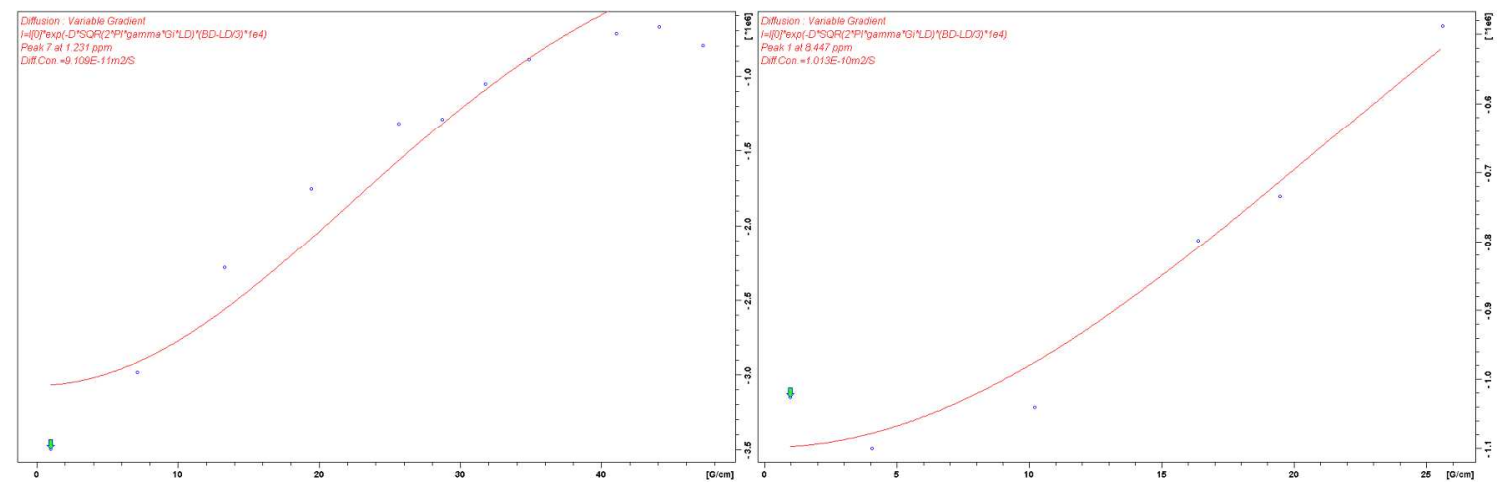

Figure S10. Nonlinear least-square analysis of the pulse-field gradient (PFG) NMR spectroscopic measurements for complex $\mathbf{1} \subset \mathbf{4}\left([\mathbf{1}]=[\mathbf{4}]=0.3 \mathrm{mM}\right.$ in $\mathrm{D}_{2} \mathrm{O}$ at $\left.298.0 \mathrm{~K}\right)$ gave the apparent diffusion coefficient for basket $1 D^{(1 \subset 4)}=0.91 \pm 0.07 \times 10^{-10} \mathrm{~m}^{2} / \mathrm{s}$ (left) and for guest $4 D^{(1 \subset 4)}=1.01 \pm 0.01 \times 10^{-10} \mathrm{~m}^{2} / \mathrm{s}$ (right). 


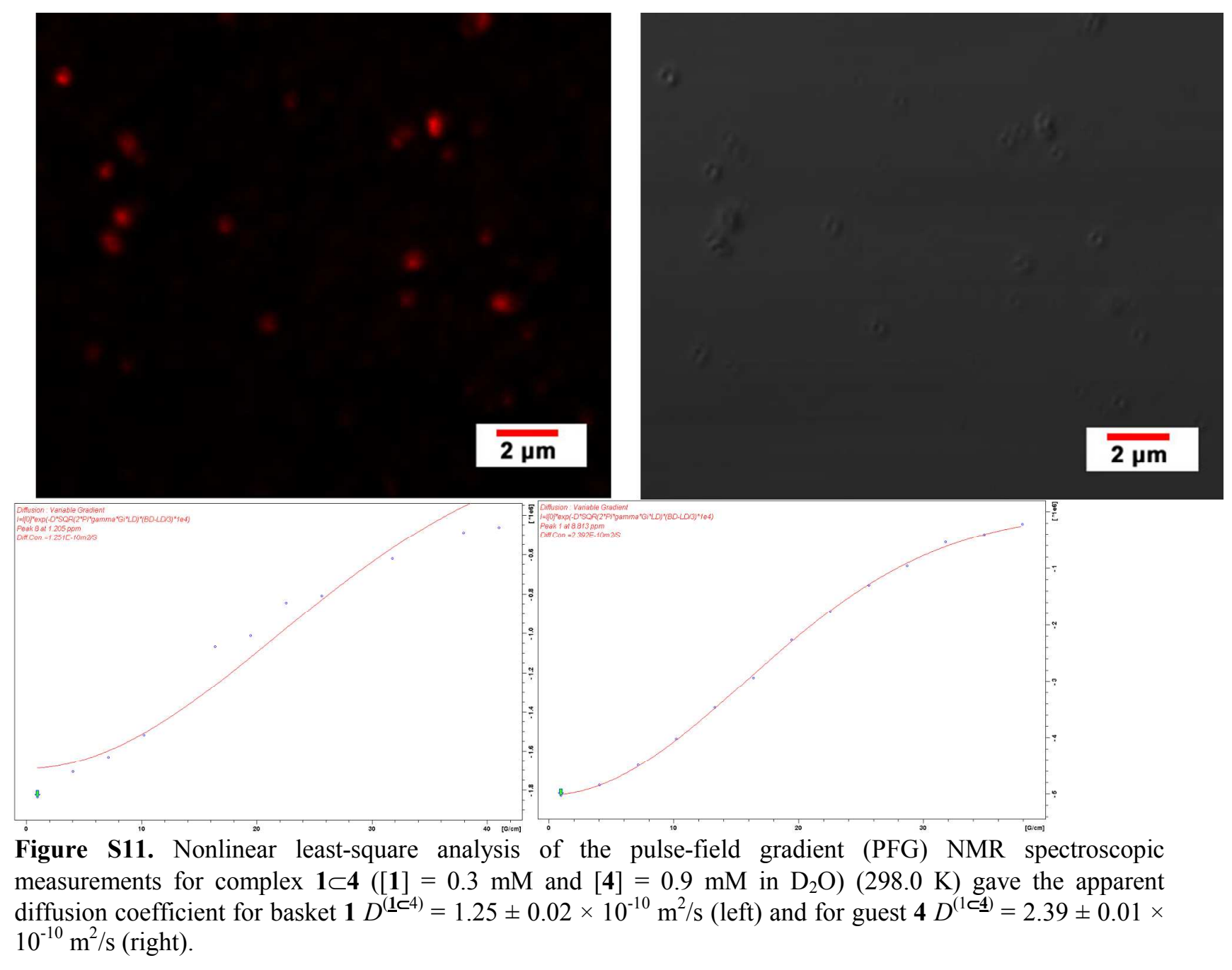

Figure S12. An aqueous solution of $1(0.2 \mathrm{mM}, 50 \mu \mathrm{L})$, rhodamine B $(2.0 \mathrm{mM}, 50 \mu \mathrm{L})$ and paraquat $5(4.0$ $\mathrm{mM}, 2.5 \mu \mathrm{L}$ ) was dialyzed (dialysis tubing with MWCO, $3.5 \mathrm{kD}$ ) against $200 \mathrm{~mL}$ of neat water at $298 \mathrm{~K}$. Laser scanning confocal microscopy images (LSCM, left) and differential interference contrast optical microscopy (DIC, right) images of a sample from the dialysis tube were obtained ( 24 hours after the dialysis was initiated) to confirm the encapsulation of dye molecules residing inside vesicles. 
The dual cavity basket was optimized using Becke's three-parameter hybrid exchange functional combined with the Lee-Yang-Parr correlation functional (B3LYP) and the $6-31+\mathrm{G}^{*}$ basis set as implemented in Gaussian 09. ${ }^{1-4}$ A partial atomic charge calculation was performed with the Merz-Kollman scheme (B3LYP/6$\left.31+\mathrm{G}^{*}\right)$.

Molecular dynamic simulations were prepared with the ACPYPE program and the necessary tools in GROMACS 4.6.3. ${ }^{7,8}$ The structure was solvated in water and neutralized. Before the $5 \mathrm{~ns}$ MD simulation was performed the energy of the system was minimized and the temperature and pressure of the system were equilibrated. The OPLS force field was used for the 5 ns MD simulation. ${ }^{9}$ The basket was then mapped for coarse-grained simulations using the scheme shown in Figure S13. A total of 36 Martini beads were used to represent the basket. ${ }^{10}$

Upon validation of the model (Table S1), Packmol was used to prepare unilamellar vesicles of various sizes. ${ }^{11}$ A $20 \mathrm{~nm}$ vesicle was prepared using 700 coarse-grained baskets, 4,200 sodium counter-ions, and 45,800 water beads with each bead representing 4 atomistic water molecules. A $50 \mathrm{~nm}$ vesicle was prepared using 3,100 coarse-grained baskets, 18,600 sodium counter-ions, and 561,400 water beads. Each system was subject to an energy minimization and subsequent temperature and pressure equilibrations prior to running MD simulations. A $1250 \mathrm{~ns}$ MD simulation was performed for the $20 \mathrm{~nm}$ vesicle and a $10 \mathrm{~ns}$ MD simulation was performed for the $50 \mathrm{~nm}$ vesicle. 

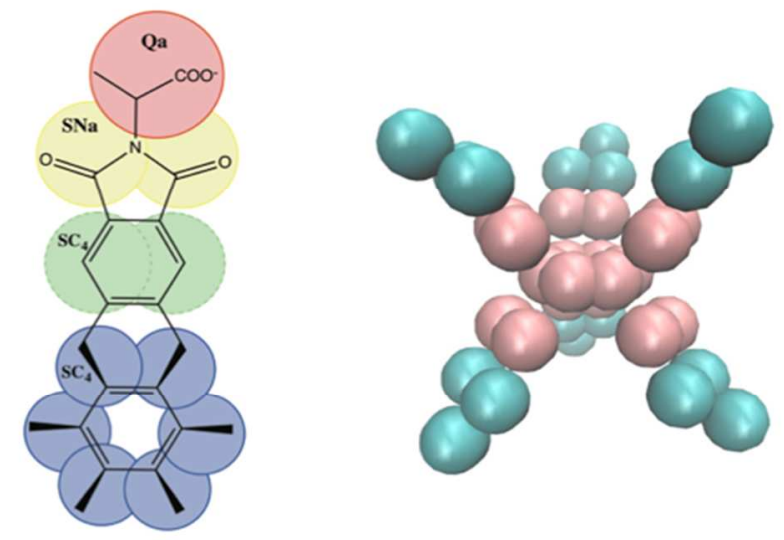

Figure S13: The mapping scheme and bead type used for the coarse-grained model (left) and the coarsegrained basket (right).

In order to validate the coarse-grained model, the average distance between each of arm was measured and compared to the atomistic MD simulation. This is show below in Table SX. The mapped MD trajectory is in agreement with the atomistic model as well as the previously published electronic structure theory investigation of the dual cavity basket's flexibility.

\begin{tabular}{|c|c|c|c|c|}
\hline \multirow{2}{*}{$\begin{array}{c}\text { Distance to be } \\
\text { Measured }\end{array}$} & \multicolumn{2}{|c|}{ Atomistic Model } & \multicolumn{2}{|c|}{ Coarse Grained Model } \\
\hline & $\begin{array}{c}\text { Average } \\
\text { Distance }(\mathrm{nm})\end{array}$ & $\begin{array}{l}\text { Standard } \\
\text { Deviation }\end{array}$ & $\begin{array}{c}\text { Average } \\
\text { Distance }(\mathrm{nm})\end{array}$ & $\begin{array}{l}\text { Standard } \\
\text { Deviation }\end{array}$ \\
\hline Arm 1: Arm 2 & 0.7755 & 0.060 & 0.7814 & 0.024 \\
\hline Arm $2:$ Arm 3 & 0.7719 & 0.075 & 0.8059 & 0.022 \\
\hline Arm $1:$ Arm 3 & 0.7806 & 0.066 & 0.8215 & 0.025 \\
\hline Arm $4:$ Arm 5 & 0.7776 & 0.066 & 0.7795 & 0.023 \\
\hline Arm $5:$ Arm 6 & 0.7764 & 0.066 & 0.7850 & 0.028 \\
\hline Arm $4:$ Arm 6 & 0.7781 & 0.059 & 0.7831 & 0.027 \\
\hline
\end{tabular}

Table S1: Validation of the coarse-grained model shown by measuring the distance between each arm of the basket. 


\section{References:}

(1) Becke, A. D. J. Chem. Phys. 1988, 88, 1053-1062.

(2) Lee, C.; Yang, W.; Parr, R. G. Phys. Rev. B 1988, 37, 785-789.

(3) Frisch, M. J.; Pople, J. A.; Binkley, J. S. J. Chem. Phys. 1984, 80, 3265-3269.

(4) Frisch, M. J. Gaussian 09, Revision A.02. Gaussian 09, Revision A.02, 2009.

(5) Breneman, C. M.; Wiberg, K. B. J. Comput. Chem. 1990, 11, 361-373.

(6) Singh, U. C.; Kollman, P. a. J. Comput. Chem. 1984, 5, 129-145.

(7) Sousa da Silva, A. W.; Vranken, W. F. BMC Res. Notes 2012, 5, 367.

(8) Van Der Spoel, D.; Lindahl, E.; Hess, B.; Groenhof, G.; Mark, A. E.; Berendsen, H. J. C. J. Comput. Chem. 2005, 26, 1701-1718.

(9) Kaminski, G. A.; Friesner, R. A.; Tirado-Rives, J.; Jorgensen, W. L. J. Phys. Chem. B 2001, $105,6474-6487$.

(10) Marrink, S. J.; Risselada, H. J.; Yefimov, S.; Tieleman, D. P.; De Vries, A. H. J. Phys. Chem. B 2007, 111, 7812-7824.

(11) Martínez, L.; Andrade, R.; Birgin, E. G.; Martínez, J. M. J. Comput. Chem. 2010, 31, 2967-2970. 